Cahiers $d u$ MONDE RUSSE

\section{Cahiers du monde russe}

Russie - Empire russe - Union soviétique et États indépendants

$51 / 4 \mid 2010$

Sciences humaines et sociales en Russie à l'Âge d'argent

\title{
Sandra Budy, Nikolaus Katzer, Alexandra Köhring, Manfred Zeller, eds., Euphoria and Exhaustion
}

\section{Sylvain Dufraisse}

\section{(2) OpenEdition}

\section{Édition électronique}

URL : https://journals.openedition.org/monderusse/7409

DOI : $10.4000 /$ monderusse. 7409

ISSN : $1777-5388$

\section{Éditeur}

Éditions de l'EHESS

\section{Édition imprimée}

Date de publication : 25 novembre 2010

Pagination : 750-755

ISBN : 978-2-7132-2316-7

ISSN : $1252-6576$

Référence électronique

Sylvain Dufraisse, «Sandra Budy, Nikolaus Katzer, Alexandra Köhring, Manfred Zeller, eds., Euphoria and Exhaustion », Cahiers du monde russe [En ligne], 51/4 | 2010, mis en ligne le 09 septembre 2013, consulté le 03 septembre 2022. URL : http://journals.openedition.org/monderusse/7409; DOI : https://doi.org/10.4000/monderusse.7409

Ce document a été généré automatiquement le 3 septembre 2022. 


\title{
Sandra Budy, Nikolaus Katzer, Alexandra Köhring, Manfred Zeller, eds., Euphoria and Exhaustion
}

\author{
Sylvain Dufraisse
}

\section{RÉFÉRENCE}

Sandra Budy, Nikolaus KATZER, Alexandra KöHRING, Manfred ZelLER, eds., Euphoria and

Exhaustion. Modern Sport in Soviet Culture and Society. Francfort-sur-le-Main New-York : Campus Verlag, 2010, 359 p.

1 L'étude du sport et de la culture physique soviétiques connaît aujourd'hui un regain d'intérêt et cet ouvrage en est la preuve manifeste. Ce volume rassemble les contributions d'un colloque qui s'est tenu à l'université Helmut Schmidt de Hambourg les 5 et 6 septembre 2008. S'inscrivant dans la lignée des travaux récents sur ce thème ${ }^{1}$, il rassemble des historiens venus d'horizons différents, tant historiques que géographiques (Allemagne, Suisse, Ukraine...).

Professeur à l'université de Hambourg, Nikolaus Katzer a fédéré une équipe de recherche autour de la question de la culture physique soviétique, axée sur l'histoire du sport et l'histoire du corps, dont il souligne en introduction l'intérêt et l'actualité. Les innombrables records et médailles récoltés par les sportifs soviétiques ont constitué l'un des résultats les plus impressionnants de l'URSS, mais ne sont devenus un objet de recherche historique que récemment, dans la lignée des travaux pionniers de James Riordan $^{2}$ et de Robert Edelman ${ }^{3}$. On assiste aujourd'hui à une ouverture et à un profond renouvellement de ces horizons. Cette compilation d'articles en est l'exemple; elle se veut un travail préparatoire qui jette les fondations d'un débat international sur ce nouveau champ et contribue à l'élargir. Selon Katzer, la culture physique doit être comprise comme s'inscrivant dans le phénomène de modernisation de l'URSS et pensée comme permettant de modifier l'humain. Le volume répond à cette première attente, 
mais il va plus loin en montrant combien le sport a été utilisé comme un instrument de discipline sociale, de construction de nouvelles hiérarchies, d'images nationales, comme un moyen pour l'État de projeter une image de lui-même.

3 L'ouvrage s'articule autour de trois parties: "Sites and Media», "Milieus and Memory ", "Gender and Science». La première rassemble des articles qui, tous, s'appuient sur des sources iconographiques (photographies, plans, peintures, sculptures) et démontrent la place du sport dans la culture visuelle, suivant ainsi les pistes de recherche lancées par Mike O'Mahony. Ekaterina Emeliantseva aborde la question du lien entre sport et topographie sociale à Saint-Pétersbourg à la fin de l'époque impériale. À partir de photographies, l'auteur cherche à démontrer comment les différentes représentations de la pratique et de la vie sportives et des nouveaux lieux qui l'accueillaient, contribuaient à façonner les images des quartiers et participaient à leur valorisation sociale. Alexandra Köhring s'intéresse, quant à elle, aux différents projets ébauchés dans les années 1920 de «Stade rouge " pour Moscou (projets tous inaboutis), et montre combien s'entremêlaient autour de ce dessein des considérations architecturales, idéologiques et techniques. Le stade devait permettre une participation active des citoyens, s'appuyait sur les conceptions nouvelles du corps et était censé contribuer, de par son architecture, à la transformation des citoyens. Sandra Budy propose une analyse de la photographie sportive dans la presse (Fizkul'tura i sport, Krasnyj sport, Sovetskoe foto ${ }^{4}$ ) des années 1920 et 1930. Du fait de l'importance de la culture physique comme vecteur de changement social, la place accordée aux représentations de sportifs s'accroît dans la presse. Dans les années 1920, celles-ci sont à l'image du foisonnement de conceptions et d'idées qui existent dans le mouvement sportif. Dans les années 1930, elles sont dominées par des portraits de sportifs et des images de parades ordonnées. L'article de Christina Kiaer aborde les représentations et l'expérience sportive dans les années 1930 à partir de l'exemple de nageuses - les sœurs Vtorova, en particulier Ljudmila Sergeevna. L'auteur s'appuie pour cela sur le témoignage de Ljudmila ainsi que sur l'un de ses albums personnels de photographies qu'elle confronte avec les œuvres de Dejneka la représentant; ce qui permet une comparaison entre les représentations personnelles de sa vie comme athlète et les représentations picturales réalisées par le peintre. Kiaer met en évidence la manière dont les sœurs Vtorova ont adopté dans leurs clichés personnels et dans leurs souvenirs les lieux communs des représentations officielles et ont ainsi participé, à leur mesure, à la production de l'idéologie soviétique. Deux autres articles complètent cette partie : Bettina Jungen étudie de manière rapide ce qu'elle nomme une esthétique de la discipline dans la sculpture (en particulier l'œuvre de Vera Muhina) et dans les ballets, enfin Burcu Dogramaci s'intéresse au mouvement sportif dans la république turque des années 1920 : la promotion du sport permet au nouvel État de manifester une évidente rupture en mettant en valeur la jeunesse, le corps et la volonté de moderniser le pays selon des critères européens.

La deuxième partie, intitulée "Milieus and Memory ", rassemble cinq articles autour de la mémoire des athlètes et des événements sportifs, de leur place et de leur intégration dans le récit de l'histoire de l'URSS. Karsten Brüggeman interroge le rapport entre sport et construction nationale en abordant le cas de l'Estonie au début $\mathrm{du} \mathrm{xx}^{\mathrm{e}}$ siècle. Il retrace dans un premier temps le parcours de lutteurs estoniens emblématiques (Georges Lurich, Georges Hackenschmidt, Aleksandr Aberg), représentants à la fois de l'Empire russe et de leur nationalité. Puis, étudiant le cas du club de cyclisme Kalev, il montre comment les clubs de sport pouvaient participer aux activités culturelles et politiques en faveur de l'émancipation nationale des Estoniens. La contribution d'Eva Maurer s'intéresse à 
l'alpinisme et, plus particulièrement, aux alpinistes soviétiques. Elle signale combien l'idée d'un alpinisme transcendant les classes sociales diffusée par la propagande contrastait avec la réalité. Il s'agissait de fait d'une pratique limitée socialement à ceux qui disposaient des revenus et du temps nécessaires. L'analyse permet donc de souligner la fragmentation de la société soviétique entre divers milieux socio-culturels ayant leurs propres modes de vie. Volodymir Ginda étudie, quant à lui, la pratique sportive sous l'occupation allemande de l'Ukraine et les différents aspects qu'elle revêtait. Manfred Zeller propose un article stimulant sur la mémoire de l'événement sportif. À partir de trois entretiens portant sur le football de la période du Dégel, il montre comment, dans la mémoire de cet événement, se mêlent enjeux privés et enjeux sportifs, comment un même épisode peut être relu différemment à l'aune de son vécu propre ou familial. Robert Edelman revient sur une période qu'il considère comme l'âge d'or du football soviétique (1945-1952), et sur le club Spartak au moment où les stades connaissent un afflux de spectateurs et les matchs de football un regain d'intérêt. Le Spartak devient un objet culte pour toute une partie de la population qui ne soutient ni le Dinamo, ni le CDKA, « équipes de lieutenants». Le Spartak introduit de nouvelles formes de jeu, engage des joueurs venus des minorités nationales et devient dans ces années d'aprèsguerre une équipe symbole de multiculturalisme, d'internationalisme et de fraternité. Edelman revient pour finir sur deux affaires qui attestent du soutien du public à cette équipe et ont donné lieu à de nombreuses lettres adressées aux dirigeants soviétiques : le match rejoué contre le Dinamo le 30 octobre 1949 et l'affaire Sal'nikov (transfert d'un joueur vedette du Spartak au Dinamo).

5 Le thème de la troisième partie mêle genre et sciences. Katerina Kobchenko revient sur les liens entre culture physique et émancipation des femmes dans les années 1920-1930 en s'appuyant sur les articles de la revue Fizkul'tura $i$ sport. Le sport occupe, en effet, une place d'importance dans les stratégies d'émancipation et permet de façonner une nouvelle femme. Il en résulte une augmentation de la participation féminine aux activités sportives, mais toutes ne sont pas considérées comme utiles pour les femmes, tels la boxe ou le catch. Ces articles soulignent l'intérêt du sport pour les femmes: impératifs prophylactiques, mais aussi régulation de la sexualité. L'auteur souligne également combien la représentation de la fizkul'turnica [la sportive] favorise une nouvelle image de la femme: beauté centrée sur la santé, habillée de vêtements pratiques, simples, semblables à ceux des hommes, images d'une apparente égalité. Dans les années 1930, les femmes participent également à la militarisation de la culture physique. Le tir, l'aviation deviennent très populaires, certaines qualités féminines (responsabilité, concentration) étant très appréciées dans ces activités. Devenant des modèles, les sportives (en particulier des aviatrices comme Polina Osipenko ou Valentina Grisodubova) sont investies à la fois dans leur vie familiale comme des mères aimantes, dans leur vie professionnelle et dans leur vie politique (membre du parti communiste, du žensoviet par exemple). La contribution de Hans-Joachim Braun et Nikolaus Katzer traite d'une période plus tardive et aborde un aspect jusque-là peu étudié quoique fondamental, l'histoire de l'entrainement sportif, en la reliant à l'histoire des sciences et plus spécifiquement aux transferts de techniques. Cet article stimulant montre comment émerge à la fin des années 1960 un "football scientifique ", permettant de dépasser les lieux communs occidentaux sur les équipes de football soviétiques composées de footballeurs robots. Le rôle de l'entraîneur du Dinamo de Kiev puis de l'équipe soviétique, Lobanovskij, est particulièrement mis en valeur. Footballeur et scientifique aguerri, s'appuyant sur les recherches en cybernétique, proche du centre de recherche de 
l'Institut de culture physique de Kiev, Lobanovskij introduit de nouvelles méthodes d'entraînement, visant à leur rationalisation et à l'adoption de tactiques plus efficaces. Les entraînements sont modélisés, puis différenciés selon les joueurs pour qu'ils atteignent une efficacité optimale. Les données de chaque match sont analysées sous forme de statistiques permettant une optimisation des capacités des joueurs. Cette tactique semble efficace car elle permet en 1988 au Dinamo de gagner la coupe des vainqueurs de coupe puis d'atteindre en tant que sélectionneur national la finale $d u$ championnat d'Europe 1988. Cet article démontre d'autre part la place des sciences du sport soviétique dans la modernisation du jeu et des méthodes d'entraînement. Anke Hillbrenner, à partir de deux revues, Sport in der UdSSR et Teorija i praktika fizičeskoj kul 'tury [Théorie et pratique de la culture physique], interroge la notion de ženstvennost', ou féminité, comme aspect d'une modernité brejnévienne. L'auteur suggère l'ambivalence des représentations du corps féminin dans l'idéal des genres soviétiques mais aussi en fonction de la presse (destinée à un public large, comme Sport in der UdSSR, ou à des scientifiques). La cosmonaute Valentina Tereškova en est un exemple vivant, alliant vie politique, sportive et familiale, promotion sociale et progrès technique. Cet idéal est diffusé dans le domaine sportif à travers la valorisation de sports favorisant la vitesse, l'adresse, la grâce. Hillbrenner souligne la contradiction entre des sportives non "féminines» (sœurs Press, Faina Mel'nik) et l'affirmation de plus en plus claire d'une féminité sportive. Stefan Wiederkehr revient également sur la question du genre durant la période de la guerre froide en analysant les stéréotypes concernant les sportives, à l'Ouest comme à l'Est. Il démontre que les médias occidentaux tendaient à viriliser et à évoquer la laideur des athlètes du bloc soviétique, alors qu'un telle pratique n'existait pas de manière aussi affirmée dans la presse socialiste. L'ouvrage s'achève, en guise d'épilogue, sur une analyse du film Sport, sport, Sport d'Elem Klimov (1970) par Christine Gölz. Ce film, par une structure originale, cherche à évoquer les multiples aspects du sport soviétique: instrument de pouvoir, acte culturel, pratique thérapeutique et prophylactique, moyen de promouvoir des rapprochements internationaux, mais également d'affirmer sa supériorité idéologique.

Plusieurs interrogations ou réserves demeurent cependant. La première concerne l'organisation de l'ouvrage, même si cette critique est inhérente à cette forme de publication. La cohérence des parties, voire leur logique interne, semblent parfois avoir été obtenues par défaut, comme le regroupement entre les questions de genre et de science. Les articles ne développent pas, par exemple, de lien entre ces deux aspects. Cela est manifeste également dans la deuxième partie regroupant les questions de milieux sociaux et de mémoire, où le rapport entre ces deux concepts n'est pas forcément établi dans les contributions. La présence d'un texte sur la Turquie, certes utile pour la comparaison, surprend cependant dans un volume consacré au sport soviétique. La question de la cohérence porte également sur la chronologie. La première partie porte intégralement sur la première moitié $\mathrm{du} \mathrm{xx}^{\mathrm{e}}$ siècle. Si cette période est fondamentale car fondatrice du mouvement sportif soviétique, il aurait été intéressant de voir si ces images des corps sportifs évoluaient dans la seconde moitié. La deuxième critique porte sur les sources utilisées. En effet, la majorité des articles utilise la presse, des œuvres littéraires, picturales ou filmiques, quelques-uns des témoignages, mais rares sont les articles s'appuyant sur les archives des institutions sportives nationales ou régionales, alors qu'elles sont nombreuses et encore peu défrichées. Il convient ensuite de souligner que, si les différentes formes de culture physique sont bien abordées, si le football est traité dans plusieurs articles, les autres sports qui ont fait la gloire de l'URSS et qui ont 
permis de remporter quelques-uns des succès aux Jeux olympiques et des records du monde (haltérophilie, athlétisme, gymnastique, hockey, volley-ball, basket-ball par exemple) sont étudiés de manière plus rapide, allusive, voire absents. Ils sont pourtant décisifs dans les représentations qu'ils ont façonnées des Soviétiques (et ce pas seulement en matière de genre); enfin, ils ont constitué eux aussi des champs de recherche pour améliorer la technique et rationaliser les entraînements.

7 Ce volume est néanmoins nécessaire par l'ampleur des questions et des débats qu'il soulève, par la masse de la bibliographie internationale exploitée, enfin par l'importance des pistes de recherche qu'il suggère.

\section{NOTES}

1. Mihail Prozumenščikov, Bol'šoj sport $i$ bol'šaja politika [Grand sport et grande politique], M. : Rosspen, 2004; Mike O'Mahony, Sport in the USSR, Physical Culture-Visual Culture, Londres: Reaktion Books, 2006; Barbara Keys, Globalizing Sport: National Rivalry and International Community in the 1930s, Cambridge : Harvard University Press, 2006 ; David Andrews, Stephen Wagg, éds., East Plays West : Essay on Sport and the Cold War, Londres : Routledge, 2006 ; Arié Malz, Stefan Rohdewald, Stefan Wiederkehr, éds., Sport zwischen Ost und West, Osnäbruck: Fibre Verlag, 2007 ; Robert Edelman, Spartak Moscow : A History of the People's Team in the Worker's State, Ithaca - Londres : Cornell University Press, 2009.

2. James Riordan, Sport in the Soviet Society, Londres : Cambridge University Press, 1977.

3. Robert Edelman, Serious Fun : a History of Spectator Sports in the USSR, Oxford : Oxford University Press, 1993.

4. [Culture physique et sport], [Sport rouge], [La photographie soviétique]. 